\title{
Invited Article: Indenter materials for high temperature nanoindentation
}

\author{
J. M. Wheeler ${ }^{\mathrm{a})}$ and J. Michler \\ Empa, Swiss Federal Laboratories for Materials Science and Technology, Laboratory for Mechanics of \\ Materials and Nanostructures, Feuerwerkerstrasse 39, Thun CH-3602, Switzerland
}

(Received 19 June 2013; accepted 23 September 2013; published online 18 October 2013)

\begin{abstract}
As nanoindentation at high temperatures becomes increasingly popular, a review of indenter materials for usage at high temperatures is instructive for identifying appropriate indenter-sample materials combinations to prevent indenter loss or failure due to chemical reactions or wear during indentation. This is an important consideration for nanoindentation as extremely small volumes of reacted indenter material will have a significant effect on measurements. The high temperature hardness, elastic modulus, thermal properties, and chemical reactivities of diamond, boron carbide, silicon carbide, tungsten carbide, cubic boron nitride, and sapphire are discussed. Diamond and boron carbide show the best elevated temperature hardness, while tungsten carbide demonstrates the lowest chemical reactivity with the widest array of elements. (C) 2013 AIP Publishing LLC. [http://dx.doi.org/10.1063/1.4824710]
\end{abstract}

\section{INTRODUCTION}

Elevated temperature nanomechanical testing techniques, predominantly nanoindentation and microcompression, are becoming increasingly popular ${ }^{1-9}$ due to the lower cost of sample manufacture and preparation, shrinking length scale of devices, and higher speed of indentation testing. Most commercial nanoindentation system manufacturers now offer a high temperature option, and these have had varying degrees of success. The main factors determining the stability of a system during high temperature nanoindentation are the thermal controls implemented in the system: ${ }^{9}$ indenter and/or sample heating, water-cooling, heat-shielding, etc. These vary between manufacturers due to the different thermal controls possible with each system configuration. In Figure 1, the maximum published indentation temperatures are shown for each system configuration as a function of publication year. Also, the total number of high temperature nanoindentation papers per year, ${ }^{10}$ as of the publication of this work, is presented. The increasing trend in popularity/availability of elevated temperature nanoindentation is clear.

System configuration plays a significant role in the feasibility of high temperature nanoindentation. Nearly all instrument developers are currently extending and advertising increased temperature ranges; however, here we will only consider results published in peer-reviewed journals. Systems featuring a horizontal pendulum were adapted for elevated temperature testing early on with both indenter and sample heating. The horizontal pendulum allows convection to vertically remove heat from the sensor region, and using indenter and sample heating allows isothermal testing ${ }^{7}$ to prevent thermal expansion during contact which results in thermal drift. This system configuration has been the most prolific in high temperature nanoindentation publications thus far. A plateau was observed in the maximum achieved temperature at $\sim 500{ }^{\circ} \mathrm{C}$ for nearly a decade, due to the onset of oxidation of diamond indenters at $\sim 400{ }^{\circ} \mathrm{C},{ }^{11}$ but this was recently overcome using high vacuum techniques. ${ }^{8}$

\footnotetext{
a)E-mail: Jeffrey.Wheeler@empa.ch
}

The second most prolific system configuration features an electrostatic actuator with heating only on the sample side. The electrostatic actuator is limited to lower forces, which necessitates that the indenter itself has a low mass. This small size minimizes the dimensions for thermal expansion and allows for rapid thermal equilibration of the indenter mass. The vertical arrangement of the system introduces the danger of convective heating of the sensors, but has been countered using water-cooling and partial vacuum. ${ }^{4}$ Without active indenter heating, thermal drift is still an issue with this system, so testing is generally limited to short durations (1-10 s). New dynamic techniques ${ }^{12}$ may provide a countermeasure for this, but significant temperature gradients will still likely be present, resulting in poor surface temperature precision.., 13

Systems with electromagnetic actuators have been limited to lower temperatures $\left(\sim 200^{\circ} \mathrm{C}\right)$ due to excessive thermal drift from heat flow between the heated sample and passively heated indenter solenoid. Dynamic techniques ${ }^{12}$ have been demonstrated to counter thermal drift with this system, but the same temperature confidence issues remain.

Recently, two new system configurations have emerged. A system featuring dual indenters to provide active surface referencing to eliminate thermal drift and frame compliance ${ }^{14}$ has been successfully demonstrated at $110^{\circ} \mathrm{C}$. Another system features a piezoelectric actuator for displacement control, indenter tip and sample heating to prevent thermal drift, and water-cooling of the system frame using an ethylene glycol and water mixture as coolant. It operates in situ in the scanning electron microscope allowing observation of deformation mechanics, and the high vacuum of the electron microscope also prevents sample and indenter oxidation. ${ }^{9}$

The increasing popularity and availability of systems capable of nanoindentation testing at high temperatures reintroduces challenges for indenter material selection which were addressed during the first advent of hot hardness testing. With the smaller length scales and greater precision involved in instrumented nanoindentation testing than hot hardness testing, a review of indenter materials and their properties with a view towards high temperature nanoindentation may be useful to many practitioners. 


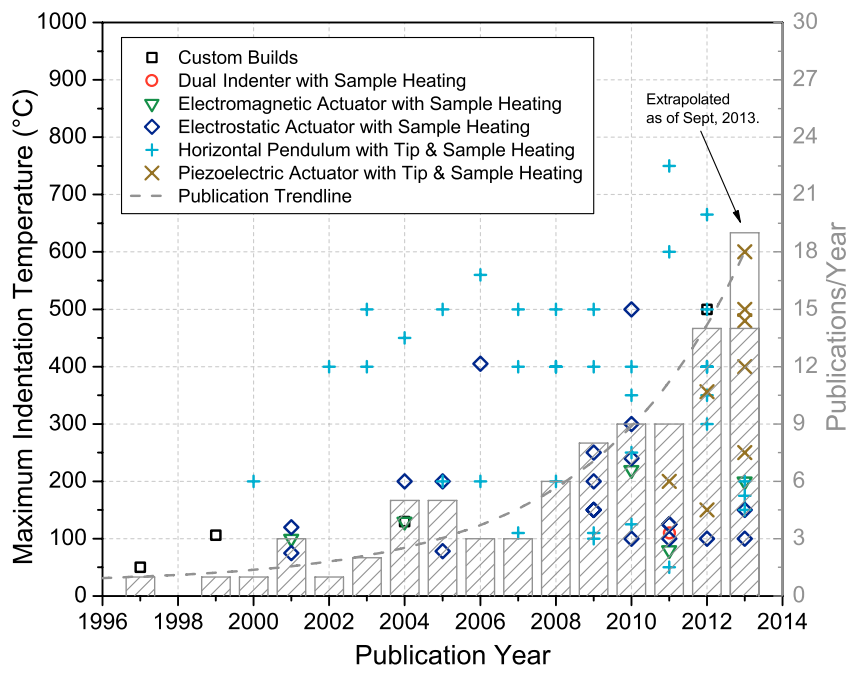

FIG. 1. Maximum published indentation temperatures for various system configurations and publications per year in recent years. ${ }^{10}$

At room temperature, the decision of which indenter to use is mainly one of geometry: What shape of indenter will best allow measurement of the property of interest? The choice of which indenter material to use is usually obvious: diamond. Occasionally other indenter materials, such as sapphire or $\mathrm{Al}_{2} \mathrm{O}_{3}$, are also desirable for conospheroidal indenters, since they can be machined into more perfectly spherical tips than diamond. But primarily, the choice of indenter is based mainly on what is the hardest, highest stiffness material available.

This is a good criterion, since it ensures against fracture (Figure 2) and ensures that the indenter receives the least amount of blunting or wear possible from the high reciprocal stresses it might experience during indentation. However, at elevated temperatures, there are several addition criterions for selection of indenter material. Will the material remain inert in the high temperature environment? At the desired temperature, is this material still the hardest, highest stiffness material available? Will the indenter material remain chemically inert and not react with the sample at temperature?

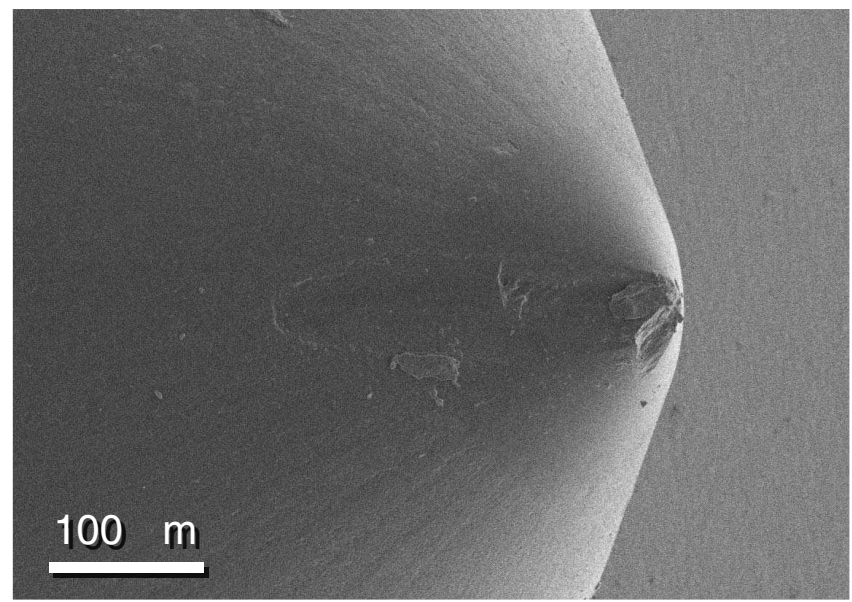

FIG. 2. Secondary electron micrograph of a damaged conospheroidal diamond indenter.
The material of choice for a specific high temperature indentation test must satisfy all these criteria. Furthermore, the properties of this material must be well-characterized as a function of temperature, so that its properties at the test temperature can be used to analyze the resulting loaddisplacement relationships. In this article, the existing literature on the high temperature $\left(\leq 1200^{\circ} \mathrm{C}\right)$ properties of diamond and the hardest borides, carbides, and nitrides will be examined with respect to their usage as indenter materials.

\section{HOT HARDNESS}

\section{A. Overview of indenter materials}

In order to perform a hardness test, the indenter material must be a minimum of $20 \%$ higher hardness than the sample in order to generate plastic deformation. ${ }^{15,16}$ In order to avoid rapid blunting or failure of a sharp indenter tip, the indenter material should be significantly $(>100 \%-1000 \%)$ harder than the sample. To provide an overview of the hot hardness of various indenter materials, the data shown in Figure 3 have been assembled.

Diamond is the obvious frontrunner for hardness at ambient temperature, but its hardness decreases somewhat rapidly at elevated temperature. By $1200^{\circ} \mathrm{C}$, the Knoop hardness of diamond approaches the hardness of graphite, which is sensible since diamond is metastable and can transform into graphite near this temperature at ambient/low pressure. $^{24}$ However, at temperatures below $1000^{\circ} \mathrm{C}$, diamond is still the hardest material available and is recommended for testing of very hard materials, such as ceramics, tool bit coatings, semiconductors, et cetera. Significant mechanical wear of diamond indenters should be expected during testing hard materials at high temperatures.

The next hardest material at ambient temperature is cubic boron nitride $(\mathrm{cBN})$. However, its hardness decreases very quickly with temperature, and it retains only half of its hardness by $500^{\circ} \mathrm{C}$. This may be due to the data originating from a polycrystalline sample, as discussed in Sec. II B. Vickers

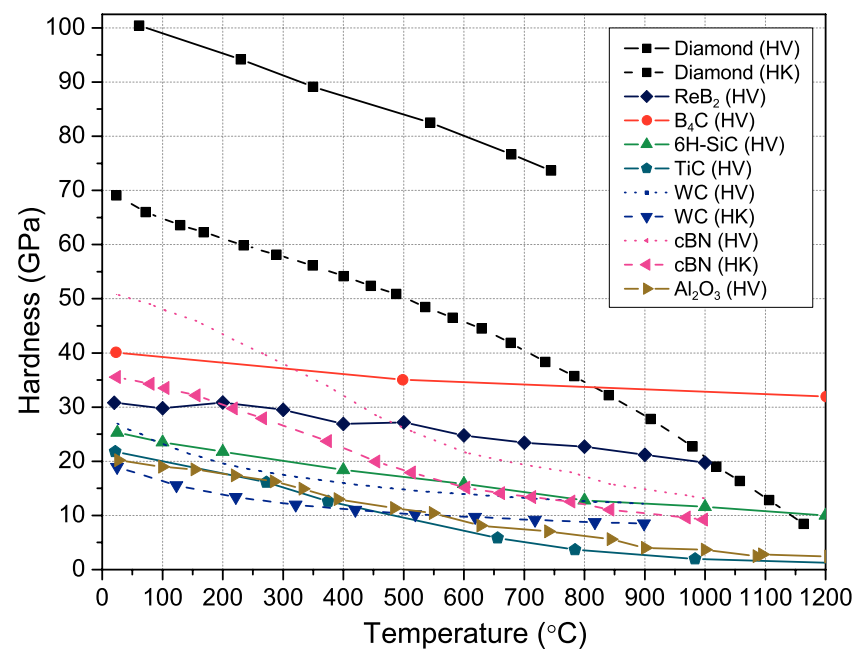

FIG. 3. Hot Vickers and Knoop hardness of indenter materials as a function of temperature ${ }^{17-23}$ with extrapolated Vickers hardness shown as dotted lines for materials where only Knoop hardness data were available. 
hardness (HV) was extrapolated for $\mathrm{cBN}$ and WC using the same scaling ratio observed between Vickers and Knoop hardness $(\mathrm{HK})$ in diamond. Boron carbide $\left(\mathrm{B}_{4} \mathrm{C}\right)$, silicon carbide ( $\mathrm{SiC}$ ), and tungsten carbide (WC) maintain their hardness at elevated temperatures significantly better. Boron carbide maintains its hot hardness best of all materials; by $900{ }^{\circ} \mathrm{C}$, its hardness surpasses diamond.

Polycrystalline, sintered boride ceramics such as $\mathrm{TiB}_{2}$, $\mathrm{ZrB}_{2}$, and $\mathrm{HfB}_{2}$ have been used previously as high temperature indenter materials to good effect, ${ }^{22}$ but further single crystal data are needed for determining their suitability for high temperature nanoindentation. Single crystal hot hardness data are available for the hardest of the borides, Rhenium diboride $\left(\mathrm{ReB}_{2}\right)$, and it retains its high hardness very well at elevated temperatures. ${ }^{23}$ However, apart from its hardness, very few of its single crystal properties are known as of yet. Due to this lack of available data, borides will not be discussed further in this work despite their promising performance.

In summary, diamond and boron carbide appear to be the materials of choice for indenting hard materials at elevated temperatures. However, additional concerns such as indenter/sample reactivity might make other materials with lower hardness have a chemical advantage for indenting specific materials systems. This is further discussed in Sec. V.

\section{B. Effect of single crystals vs. polycrystals}

One shortcoming of Sec. II A is that the available literature does not include single crystal data for cubic boron nitride. Since indenters for nano-scale measurements will almost certainly be using a single crystal at the functional tip of the indenter, it is the single crystal plastic behavior which is relevant for its high temperature indentation performance. The difference between single and polycrystalline behavior in these materials at elevated temperatures has been well illustrated ${ }^{18}$ for tungsten carbide - Figure 4.

Polycrystalline tungsten carbide is observed to be significantly harder and show decreased temperature dependence at low temperatures $\left(<700^{\circ} \mathrm{C}\right)$ compared to single crystalline

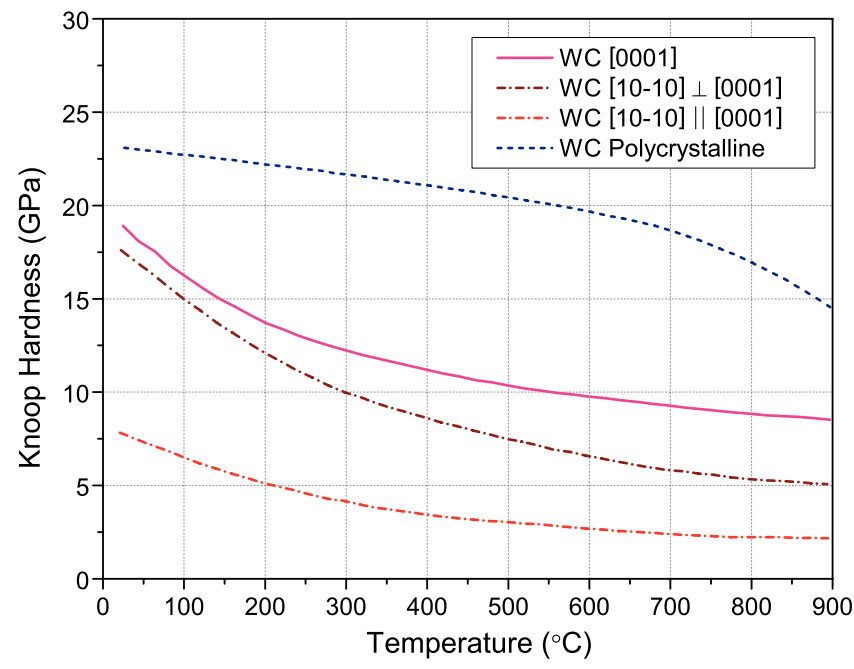

FIG. 4. Hot Knoop hardness of single crystal tungsten carbide of various orientations and polycrystalline tungsten carbide. ${ }^{18}$ material. This is attributed to the additional difficulty of propagating dislocations across grain boundaries, so strength will also be dependent on the grain size following Hall-Petch behavior.

Single crystal behavior for WC is highly anisotropic with temperature dependence also varying between various crystal orientations. This dependence will be less for cubic crystals than hexagonal indenter materials such as $\mathrm{WC}, \mathrm{Al}_{2} \mathrm{O}_{3}$, and $6 \mathrm{H}-\mathrm{SiC}$. This highlights the importance of correctly orienting these crystals during indenter manufacture.

The cBN hot hardness values in Figure 3 are from a polycrystalline sample with a $5 \mu \mathrm{m}$ grain size. ${ }^{17}$ This might be partially responsible for the relatively rapid decrease in hot hardness with temperature observed. Higher hardnesses without a rapid decrease in hardness at high temperature were observed in finer grain size cBN; however, it is not possible to speculate how a single crystal would behave. This suggests that nanocrystalline materials may have higher hardness with lower temperature dependence as well as effectively isotropic elastic properties, but it is likely that grain growth and lower temperature onset of rapid hardness decrease would limit their usefulness to lower temperatures.

\section{New candidate indenter materials}

Significant effort ${ }^{21,25-29}$ has been made recently for creating new superhard materials for industrial abrasives, hard coatings, and various other applications. Several new materials of high hardness have been discovered: $\mathrm{ReB}_{2},{ }^{23,25}$ $\mathrm{B}_{6} \mathrm{O},{ }^{30} \mathrm{BC}_{5},{ }^{26} \mathrm{BC}_{2} \mathrm{~N},{ }^{27} \gamma$-Boron, ${ }^{28}$ and aggregated diamond nanorods. ${ }^{29}$ However, several challenges still remain before these materials can be considered as candidates for elevated temperature indenter materials: cost, availability of large single crystals, and knowledge of material properties at elevated temperatures.

\section{ELASTIC MODULUS}

\section{A. Indentation modulus analysis}

One of the chief advantages of instrumented indentation over previous hot hardness methods is the ability to extract hardness and elastic modulus without imaging of the residual impression. This is achieved by measuring the stiffness of the contact during unloading of the indenter to determine the contact area and from that the hardness and modulus. This can be achieved by various different analyses, but the standard analysis is the one outlined by Oliver and Pharr. ${ }^{31}$ In this analysis, since the indenter tip is not perfectly rigid, it elastically deforms simultaneously with the sample. Assuming the elastic constants are isotropic, it can be shown that the apparent or "reduced" modulus, $E_{r}$, is given by

$$
E_{r}=\frac{\sqrt{\pi}}{2 B} \frac{S}{\sqrt{A_{p}}},
$$

where $B$ is a geometric constant, $S$ is the contact stiffness, and $A_{p}$ is the contact area. This reduced modulus is the convolution of both the indenter and sample elastically deforming 
during contact according to the relation

$$
E_{r}=\left(\frac{\left(1-v_{s}^{2}\right)}{E_{s}}+\frac{\left(1-v_{i}^{2}\right)}{E_{i}}\right)^{-1},
$$

where $E_{i}, v_{i}$ and $E_{s}, v_{s}$ are the Young's modulus and Poisson's ratio of the indenter and sample, respectively. This equation demonstrates necessity of accurate knowledge of the indenter properties in order to apply instrumented indentation to measure the mechanical properties of a sample.

\section{B. Temperature dependence of modulus}

Since the values of Young's modulus, as well as all other mechanical properties, change with temperature, it is important to know the correct values of the indenter's elastic properties at the test temperature in order to accurately extract sample properties at that temperature. An illustration of the change in elastic properties of various indenter materials with temperature is shown in Figure 5.

The raw data for Young's modulus as a function of temperature shown in Figure 5 are taken from various literature sources. ${ }^{32-39}$ The fitted lines shown connecting the points are a regression fit to Wachtman's equation: ${ }^{35}$

$$
E=E_{0}-C T \exp \left(\frac{-T_{0}}{T}\right),
$$

where $E_{0}$ is the Young's modulus at $0^{\circ} \mathrm{K}, C$ is an exponential fitting parameter, and $T_{0}$ is the elevated temperature in ${ }^{\circ} \mathrm{K}$ where the Young's modulus approaches a linear relationship with temperature. A summary of the parameters used to fit the data in Figure 5 is given in Table I. This equation also accommodates the athermal regime at low temperatures and yields values which approach $0{ }^{\circ} \mathrm{K}$ with zero slope in accordance with the third law of thermodynamics. Poisson's ratio also changes as a function of temperature, but both the magnitude of this change and its effect on indentation results are suggested to be almost negligible.

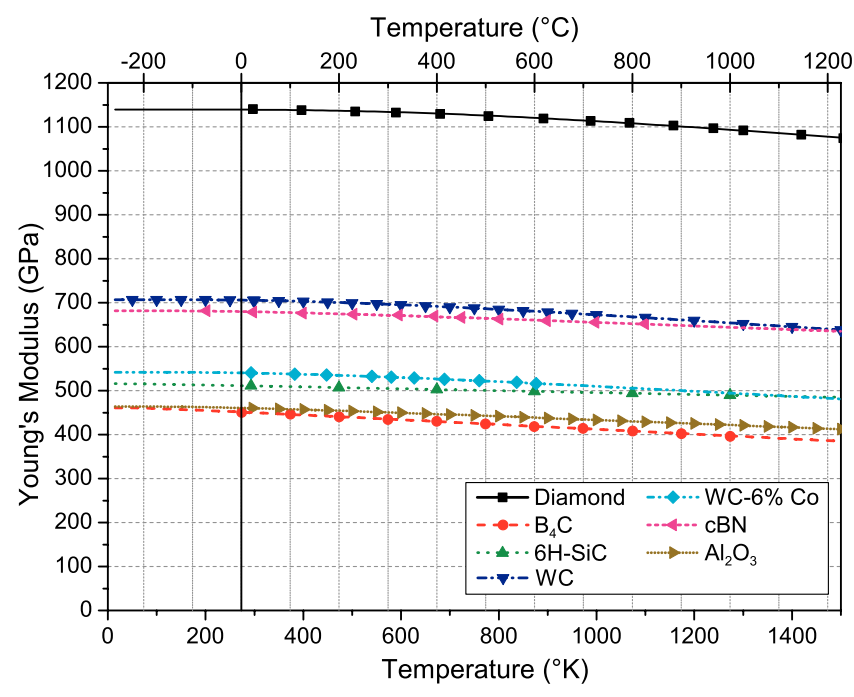

FIG. 5. Young's modulus of indenter materials as a function of temperature. ${ }^{32-39}$
TABLE I. Summary of elastic parameters for Eqs. (2) and (3) for various indenter materials. ${ }^{32-39}$

\begin{tabular}{lcccc}
\hline \hline Material & $\mathrm{E}_{0}(\mathrm{GPa})$ & $\mathrm{C}$ & $\mathrm{T}_{0}\left({ }^{\circ} \mathrm{K}\right)$ & $\begin{array}{c}\text { Poisson's } \\
\text { ratio, } v\end{array}$ \\
\hline $\begin{array}{l}\text { Diamond, type IIa } \\
\text { Boron carbide, }\end{array}$ & $\begin{array}{c}1139.2 \\
\mathrm{~B}_{4} \mathrm{C}\end{array}$ & 0.1109 & 1434.8 & 0.07 \\
$\begin{array}{l}\text { Silicon carbide, } \\
\text { 6H-SiC }\end{array}$ & 515.7 & 0.0218 & 79.25 & 0.21 \\
$\begin{array}{l}\text { Tungsten carbide, } \\
\text { WC }\end{array}$ & 706.7 & 0.0824 & 879.64 & 0.194 \\
$\begin{array}{l}\text { Tungsten carbide } \\
\text { with 6\% cobalt, }\end{array}$ & 541.7 & 0.0648 & 707.91 & 0.20 \\
$\begin{array}{l}\text { WC-6\% Co } \\
\text { Cubic boron } \\
\text { nitride, cBN }\end{array}$ & & & & \\
\begin{tabular}{l} 
Sapphire, $\mathrm{Al}_{2} \mathrm{O}_{3}$ \\
\hline
\end{tabular} & 463.7 & 0.0441 & 373 & 0.15 \\
\hline
\end{tabular}

For the case of tungsten carbide indenters for macro- or micro-indentation, special caution is needed. Typically, tungsten carbide indenters are sintered cermets containing polycrystalline tungsten carbide grains and some fraction of cobalt as a binder. This has a significant effect on the elastic properties as can be seen in Figure 5. The effect of the grain size and the fraction of cobalt binder on the elastic modulus of the cermet is known, ${ }^{40}$ but specific knowledge of the exact microstructure of your indenter would be required in order to use these relationships.

\section{Effect of using incorrect modulus at temperature}

If the modulus of the indenter at ambient temperature is used for measurements taken at elevated or cryogenic temperatures, an error in measurement will occur. This error will scale directly with both the change in the indenter modulus with temperature and the difference in the modulus between the sample and indenter.

In Figure 6, the error in determining the sample modulus, $E_{s}$, is shown for the case of an idealised material with constant reduced modulus, $E_{r}$, of $200 \mathrm{GPa}$ and Poisson's ratio, $v_{\mathrm{s}}$, of 0.33 independent of temperature. This is the error that would result from using the ambient temperature values for the indenter properties to determine the sample modulus from a measured reduced modulus of $200 \mathrm{GPa}$ at different temperatures. In materials where the modulus is very low relative to the indenter modulus, this error will be smaller than shown. However, in materials which have modulus similar to that of the indenter, these errors can be very large. This can be seen in Figure 6 in the cases of boron carbide and sapphire, whose moduli are only $\sim 2.5 \times$ that of the idealized sample.

In addition to temperature, the elastic properties of materials also vary at high pressures. ${ }^{41}$ This has been shown to have an effect on indentation measurements of elastic properties of high strength/high modulus materials. ${ }^{42}$ This effect is expected to be observed during indentation at elevated temperatures, though in a diminished capacity due to the reduced stresses required for elastic/plastic deformation. 


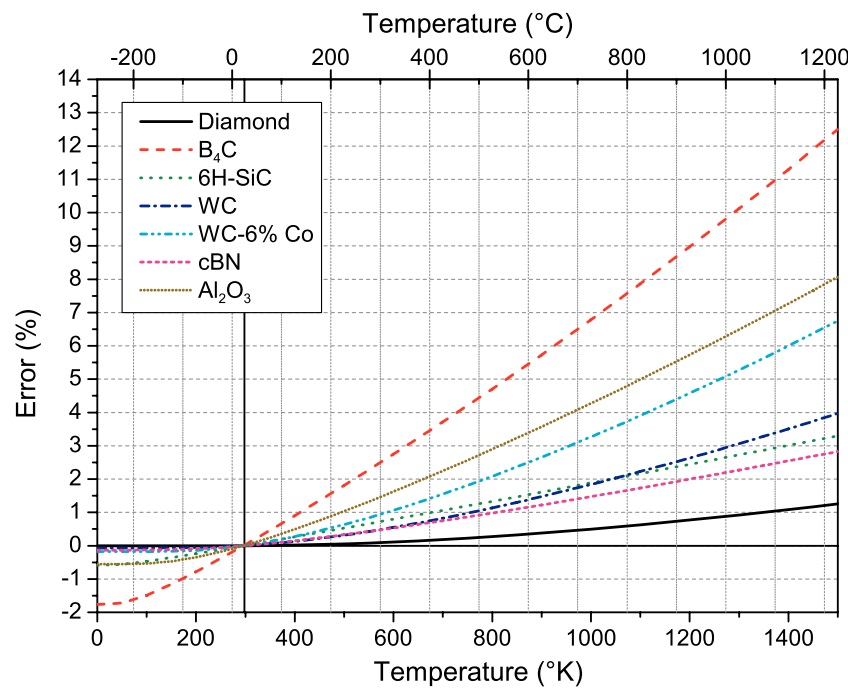

FIG. 6. Error in Young's modulus measurements on a sample with $\mathrm{E}_{\mathrm{r}}=200 \mathrm{GPa}$ and $v_{\mathrm{s}}=0.33$ from using room temperature values of indenter material moduli as a function of temperature..$^{32-39}$

\section{THERMAL PROPERTIES AND EFFECTS ON MEASUREMENT}

\section{A. Relationship of thermomechanical properties to drift}

It is well known that the thermal properties of the sample material, particularly thermal conductivity, have an effect on the magnitude of thermal drift during high temperature indentation. This has been shown to be due to the contact thermal drift being proportional to the amount of heat flow occurring across the contact. ${ }^{43}$ However, the thermal conductivity of the indenter also plays a role. The majority of the thermal drift has been attributed to expansion within the shaft of the indenter, ${ }^{4}$ so the magnitude of the indenter's expansion for a given amount of heat or $\Delta L / q$ is a descriptive parameter for the propensity of an indenter material to thermal drift. The expansion for per unit energy,

$$
\frac{\Delta L}{q}=L \frac{C_{\mathrm{p}} \alpha_{\mathrm{L}}}{\rho V},
$$

where $L$ is the axial indenter length, $q$ is the transferred heat, $C_{\mathrm{p}}$ is the specific heat, $\alpha_{\mathrm{L}}$ is the linear coefficient of thermal expansion, $\rho$ is the density, and $V$ is the volume of the indenter shaft. These properties are summarized in Table II for the various indenter materials. The geometry of the indenter material shaft is given to be $0.2 \mathrm{~mm}$ by $0.2 \mathrm{~mm}$ with an axial length of $0.3 \mathrm{~mm}$, which is then embedded during manufacture into a holder whose geometry is specific to the manufacturer of the nanoindentation system.

The amount of thermal expansion drift expected from the indenter shaft will now be a combination of the expansion per unit energy and the heat flow expected across the interface, which is a function of the indenter and sample material's thermal conductivity, the contact area, and thermal gradient. ${ }^{43}$ For an indent of a similar size on the same material with the same temperature difference, the various indenters show mostly similar behavior. Diamond and cBN both conduct heat extremely well, but their expansion per unit energy is very low. Whereas, boron carbide and sapphire are poorer conductors, but have high expansion per unit energy due to their higher coefficients of thermal expansion. Silicon carbide appears to be significantly prone to thermal drift, since it has both high conductivity and high expansion per unit energy. The best performance is expected from tungsten carbide, because it has both very low conductivity and low expansion per unit energy due to its high density.

\section{B. Indenter geometry variation with temperature}

Thermal expansion can also have an effect on the geometry of an indenter. For ideal self-symmetric indenters, such as conical and pyramidal indenters, this effect would be nominally nil, except for any anisotropy in thermal expansion coefficients causing a slight change in aspect ratio or equivalent cone angle. Some indenter materials with a hexagonal crystal structure, e.g., $6 \mathrm{H}-\mathrm{SiC}$ and $\mathrm{Al}_{2} \mathrm{O}_{3}$, do have anisotropy in thermal expansion, but we will only consider isotropic expansion here. Since indenters cannot have ideal geometry, there is always a blunt tip radius at the apex of the cone or pyramid. This radius will expand at elevated temperatures and produce a proportional change in the area function of the indenter, as has been previously discussed. ${ }^{3}$ Thus, the main consideration of the influence of thermal expansion on indenters, aside from thermal drift related expansions, is the change in tip radius, whether the tip geometry is conical, pyramidal or spherical.

TABLE II. Summary of room temperature thermomechanical properties of various indenter materials..$^{33,36,44-50}$

\begin{tabular}{lcccrr}
\hline \hline Indenter material & $\begin{array}{c}\text { Thermal conductivity } \\
\left(\mathrm{W} \mathrm{m}^{-1}{ }^{\circ} \mathrm{K}^{-1}\right)\end{array}$ & $\begin{array}{c}\text { Thermal expansion } \\
\left(10^{-6}{ }^{\circ} \mathrm{K}^{-1}\right)\end{array}$ & $\begin{array}{c}\text { Specific heat } \\
\left(\mathrm{J} \mathrm{g}^{-1}{ }^{\circ} \mathrm{K}^{-1}\right)\end{array}$ & $\begin{array}{c}\text { Density } \\
\left(\mathrm{g} / \mathrm{cm}^{3}\right)\end{array}$ & $\begin{array}{r}\Delta L / q \\
(\mathrm{~nm} / \mathrm{mJ})\end{array}$ \\
\hline $\begin{array}{l}\text { Diamond, type IIa } \\
\text { Boron carbide, }\end{array}$ & 2000 & 1.00 & 0.52 & 3.51 & 3.7 \\
$\begin{array}{l}\mathrm{B}_{4} \mathrm{C} \\
\text { Silicon carbide, } \\
\text { 6H-SiC }\end{array}$ & 28 & 4.22 & 0.96 & 2.52 & 40.2 \\
$\begin{array}{l}\text { Tungsten carbide, } \\
\text { WC }\end{array}$ & 490 & 2.77 & 0.66 & 3.21 & 14.2 \\
$\begin{array}{l}\text { Cubic boron } \\
\text { nitride, cBN }\end{array}$ & 1300 & 10.17 & 0.18 & 15.8 & 2.9 \\
\begin{tabular}{l} 
Sapphire, $\mathrm{Al}_{2} \mathrm{O}_{3}$ \\
\hline
\end{tabular} & 42 & 1.15 & 0.51 & 3.48 & 4.2 \\
\hline
\end{tabular}




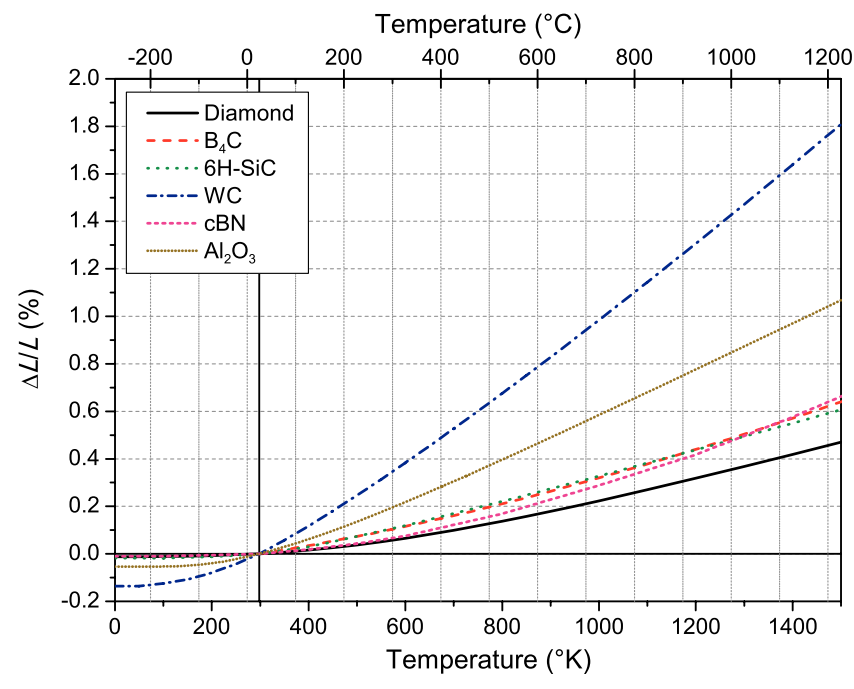

FIG. 7. Relative length change of various indenter materials compared to room temperature along their principal crystallographic axis as a function of temperature. $^{33,47-50}$

Over large variations in temperature, the coefficient of thermal expansion (CTE) cannot be approximated as linear. In order to extract the relative amount change in length, $L$, due to thermal expansion $(\Delta L / L)$, the relationship of the CTE with temperature must be integrated. For the indenter materials considered here, this relative change in dimension or tip radius with respect to room temperature is shown in Figure 7. For most materials, this is $\leq 0.5 \%$ even by $1000^{\circ} \mathrm{C}$; however, sapphire and tungsten carbide show significantly more expansion. The effect of this expansion on the projected area functions of Berkovich indenters with a $100 \mathrm{~nm}$ tip radii and $10 \mu \mathrm{m}$ radius spherical indenters is shown in Figure 8.

The differences between the Berkovich and the spherical indenters' changes in projected area at elevated temperatures can be immediately observed in Figure 8 . The spherical indenters' changes in area are initially directly equivalent to the relative length change observed in Figure 7 at this temperature for these materials, and only slight increases are observed at greater depths due to the slight increases in radii.

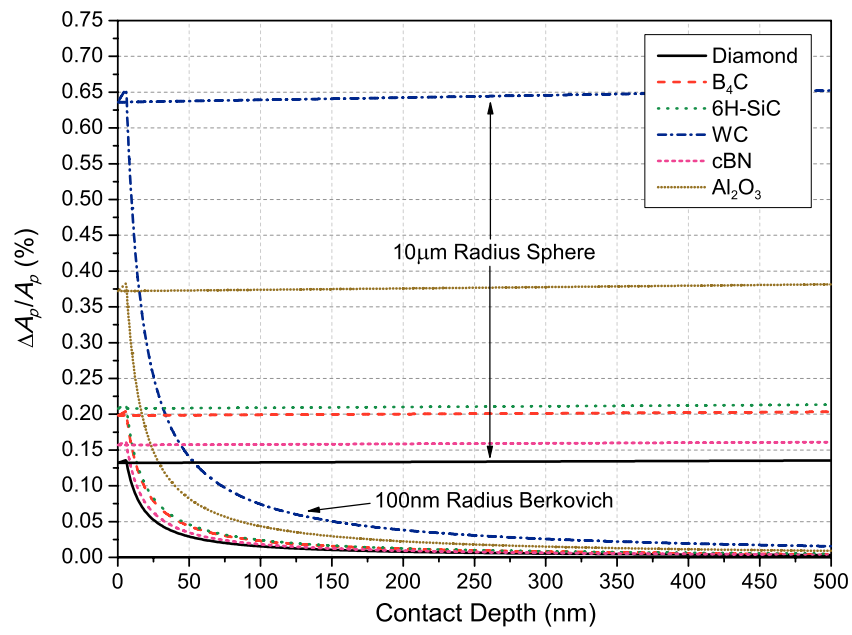

FIG. 8. The percentage change in projected area at $500{ }^{\circ} \mathrm{C}$ for Berkovich indenters with a $100 \mathrm{~nm}$ tip radius and $10 \mu \mathrm{m}$ spherical indenters composed of various indenter materials.
The Berkovich indenters initially start at the same values, due to the blunting of the tip radius, but then they rapidly decrease down to near negligible levels as the effect of the selfsymmetry becomes apparent at greater depths. The Berkovich area function is approximated here using a piecewise function where the region near the tip is approximated as a sphere perfectly tangent to the end of a cone with an angle such that its projected area is equivalent to the Berkovich pyramid:

$$
A_{p}=\pi\left(2 R h_{c}-h_{c}^{2}\right) \quad \text { when } h_{c} \leq R-R \sin (\theta)
$$

and

$$
A_{p}=\pi\left[\left(h_{c}+h_{x}\right) \tan (\theta)\right]^{2} \quad \text { when } h_{c}>R-R \sin (\theta),
$$

where $R$ is the tip radius, $h_{c}$ is the contact depth, $h_{x}$ is the additional depth to which an ideal cone tangent to the spherical tip would extend: $h_{x}=R / \sin (\theta)-R$, and $\theta$ is the cone angle: $70.32^{\circ}$ for a Berkovich.

Maxima in the changes in area are observed at the tangent depth between the spherical tip and the cone. This is the transition point between the spherical function, which has relatively larger areas at greater depths, and the self-similar conical function which has relatively the same areas at greater depths. As $h_{c}$ becomes $\gg h_{x}$, the additional influence of $h_{x}$ in Eq. (5) becomes negligible. The change in $h_{x}$ to accommodate the change in $R$ due to thermal expansion is the main source is deviation for the self-symmetric portions of the indenters. The piecewise function utilized here has the advantage of remaining accurate for low depths and/or large tip radii, whereas the continuous area function of Thurn and $\mathrm{Cook}^{51}$ used previously ${ }^{3}$ is not valid for depths where the contact radius is less than the indenter radius.

The changes in projected area calculated for diamond are greater than previously reported ${ }^{3}$ for similar temperature gradients, because the present analysis takes into account the changes in coefficients of thermal expansion at elevated temperature rather than extrapolating a room temperature value of CTE to elevated temperature. Also, the piecewise function allows accurate calculation of changes in area at low depths. However, the trends of rapid decrease in $\Delta A_{p} / A_{p}$ with increasing depth are in good agreement with previous estimations. ${ }^{3}$ The maximum error expected due to thermal expansion is on the order of $1 \%$, and this is limited to indentations where the depth is $\leq$ the indenter radius. Most indenter materials are only expected to have error on the order of $0.1 \%$, which is comparable to the accuracy of the typical indenter area function.

\section{Methods for indenter temperature calibration}

In order to minimize errors in displacement measurement due to expansions related to heat exchange between the indenter and sample at elevated temperatures, the temperatures of the indenter and the sample must be very precisely matched. Since the thermocouples for monitoring the indenter temperature are always removed some distance away from the region of contact, a thermal gradient exists between the thermocouple and the tip of the indenter. This can result in errors in indenter set temperature on the order of $5 \%-40 \% .^{9}$ In 
order to maintain accurate test temperatures, this temperature gradient must be calibrated prior to testing. Two methods have been previously described ${ }^{43}$ for this: indentation into thermocouples at high temperature and Raman spectroscopy. A third method might be use of a high resolution thermal camera calibrated to the indenter material, but this has not been experimentally demonstrated yet.

Direct indentation of thermocouples at elevated temperature allows contact to be achieved at a known surface temperature. Some error due to poor thermal coupling can always be expected when a thermocouple is merely bonded to a surface by a high temperature adhesive, and directly indenting the thermocouple removes this uncertainty. Care must be taken in thermocouple type selection to prevent corrosion of the indenter. Platinum/rhodium-based thermocouples (Types $\mathrm{B}, \mathrm{R}$, and S) are recommended for high temperature indenter temperature calibration for most indenter materials. Matching the indenter temperature to this known surface temperature can be achieved by either thermal displacement drift measurements ${ }^{7}$ or direct temperature shift measurements. ${ }^{43}$ In both cases, the technique involves varying either the indenter or the sample temperature while leaving one of them constant and performing a number of indentations at different relative temperatures. If the indenter is observed to drift in the negative displacement direction or to increase in temperature during contact, the indenter is presumed to be colder than the sample surface. If the indenter decreases in temperature or drifts in the positive displacement direction than the indenter, then the indenter is presumed to be hotter than the sample surface. Thermal drift displacement measurements are additionally affected by stabilisation of the system frame and temperature fluctuations during contact, ${ }^{9}$ so long stabilisation periods and drift hold periods may be necessary to correctly match the sample and indenter by this method. ${ }^{7}$ After performing this temperature matching procedure on a thermocouple at several different surface temperatures, the relationship between the known surface temperatures from the thermocouple and the temperatures at which the indenter apparently matches these temperatures can be ascertained.

Calibrating an indenter's temperature via Raman spectroscopy is somewhat simpler. However, the precision of these measurements is typically limited to $\sim 10^{\circ} \mathrm{C}$. When using an indenter made from a material with a known Raman shift as a function of temperature, it is fairly straightforward to heat an indenter to some fixed set temperature, obtain a Raman spectrum from the indenter and measure the peak shift, compare that peak shift to the literature, and determine the actual temperature of the indenter according to the Raman shift. The relationships for Raman shift as a function of temperature are available in the literature for many indenter materials: diamond, ${ }^{52-54} \mathrm{cBN},{ }^{55,56}$ and sapphire. ${ }^{57}$

\section{CHEMICAL REACTIVITY}

\section{A. Indenter damage due to oxidation}

The danger of oxidative damage to diamond indenters at temperatures $>400^{\circ} \mathrm{C}$ is now fairly well known $n^{4,11}$ in the community. At temperatures $\leq 400^{\circ} \mathrm{C}$, diamond indenters

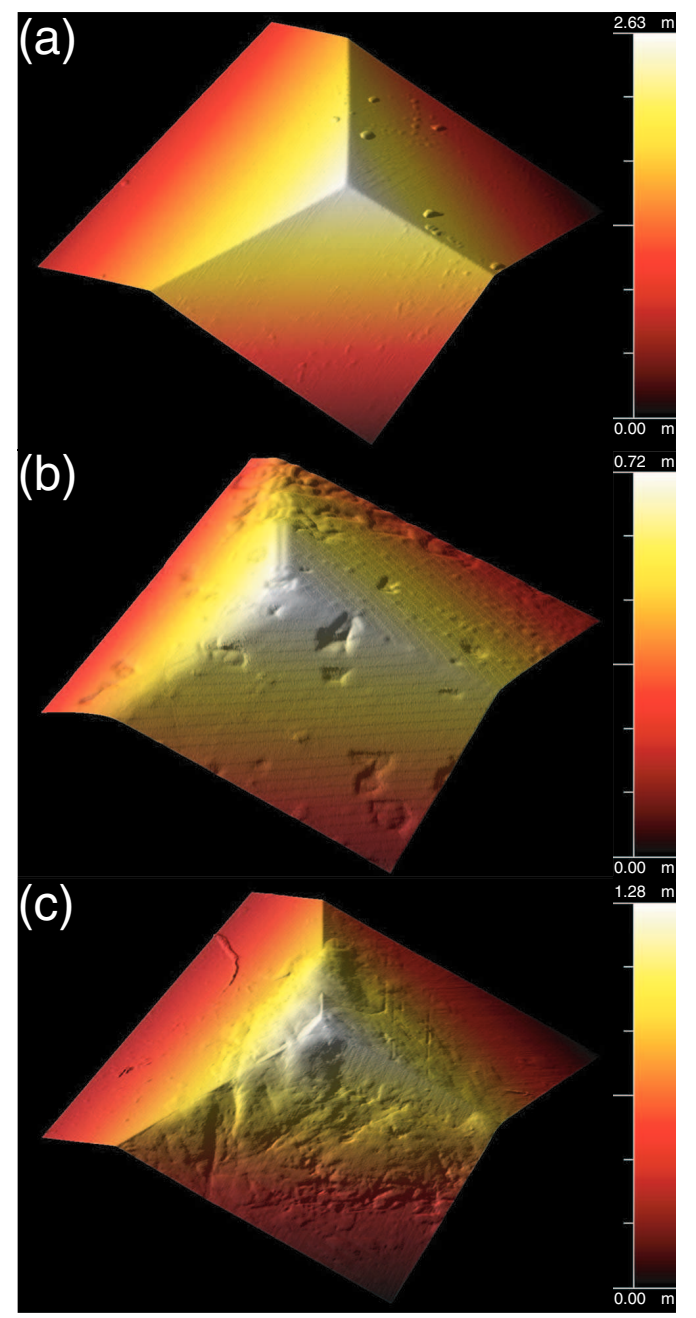

FIG. 9. AFM data shown as orthogonal 3D projections at $45^{\circ}$ inclination of Berkovich indenters (a) undamaged after long term usage at temperatures $<400{ }^{\circ} \mathrm{C},{ }^{11}$ (b) after 90 min at $900^{\circ} \mathrm{C}$ in commercial purity argon, ${ }^{11}$ and (c) after scanning an oxidized aluminium sample in air at $300^{\circ} \mathrm{C} .61,62$

can be nominally stable for years of operation as shown in Figure 9(a). Most other indenter materials are also susceptible to oxidation damage at similar or slightly higher temperatures than diamond - Table III. These onset temperatures are typical for oxidation of fine powders with sizes similar to that of sharp indenter radii. However, it is important to note that all of these onset temperatures can be reduced by the introduction of water vapour. Extra caution is warranted during testing in humid environments, since water vapour not only

TABLE III. Onset temperature and product of oxidation for various indenter materials in dry air. ${ }^{11,44,58-60}$

\begin{tabular}{ll}
\hline \hline Indenter material & \multicolumn{1}{c}{ Behavior in oxygen } \\
\hline Diamond & Forms $\mathrm{CO}$ and $\mathrm{CO}_{2}>400^{\circ} \mathrm{C}^{11}$ \\
Boron carbide, $\mathrm{B}_{4} \mathrm{C}$ & Forms $\mathrm{B}_{2} \mathrm{O}_{3}$ layer $>450^{\circ} \mathrm{C}^{58}$ \\
Silicon carbide, $6 \mathrm{H}-\mathrm{SiC}$ & Forms $\mathrm{SiO}_{2}>750^{\circ} \mathrm{C}^{59}$ \\
Tungsten carbide, WC & Forms $\mathrm{WO}_{3}>500^{\circ} \mathrm{C}^{60}$ \\
Cubic boron nitride, cBN & Form $\mathrm{B}_{2} \mathrm{O}_{3}$ layer $>700^{\circ} \mathrm{C}^{44}$ \\
Sapphire, $\mathrm{Al}_{2} \mathrm{O}_{3}$ & Inert \\
\hline \hline
\end{tabular}


decreases the onset temperatures but also increases the oxidation rates.

For operation at temperatures higher than the onset temperatures in Table III, a high purity inert gas ${ }^{4,7}$ or high vacuum $^{8,9}$ environment can be used to protect the indenter from oxygen. Otherwise, the indenter initially becomes smoothly blunted and then irregularly blunted as etch pits and terraces form on the surface ${ }^{11}$ as seen in Figure 9(b). Partial vacuum ${ }^{4}\left(\sim 10^{-2}\right.$ mbar) and commercial purity argon (30-45 $\mathrm{ppm} \mathrm{O}_{2}$ ) atmospheres ${ }^{11}$ have been observed not to significantly boost onset temperatures for oxidation of diamond: oxidation of the diamond was observed between 400 and $500^{\circ} \mathrm{C}$. High vacuum environments ${ }^{8,9}\left(\sim 10^{-6}\right.$ mbar $)$ have been successful thus far in preventing oxidation of diamond indenters up to $\sim 700^{\circ} \mathrm{C}$; however, ultra high vacuum (UHV) may be necessary for testing with diamond at temperatures up to $1000^{\circ} \mathrm{C}$.

Another kind of "damage" due to oxidation can also occur at lower temperatures. If indentations or scratches are performed in a material which oxidizes, this surface oxide can easily be transferred to the indenter tip ${ }^{61}$ as shown in Figure 9(c). This oxide contamination effectively blunts the indenter and introduces large errors into the diamond area function calibration. This form of contamination can strongly adhere to the indenter and require the use of acids or indentations into hard materials to remove it.

\section{B. Potential for indenter damage from sample}

Even if the indenter is sufficiently stiff and hard to indent the sample material without significant mechanical blunting or wear, the indenter could still be at risk to chemical reactions between itself and the sample. The classic example of this is the indentation of steel with a diamond indenter at high temperature. Despite the extraordinary chemical stability of diamond, most exemplified by its complete resistance to attack by acids, the diamond disintegrates and reacts with the steel to form $\mathrm{Fe}_{3} \mathrm{C}$ carbides. This process can completely destroy an indenter, as shown in Figure 10, to the point where only a remnant of where the indenter was can be observed afterwards. This demonstrates the necessity of using an ap-

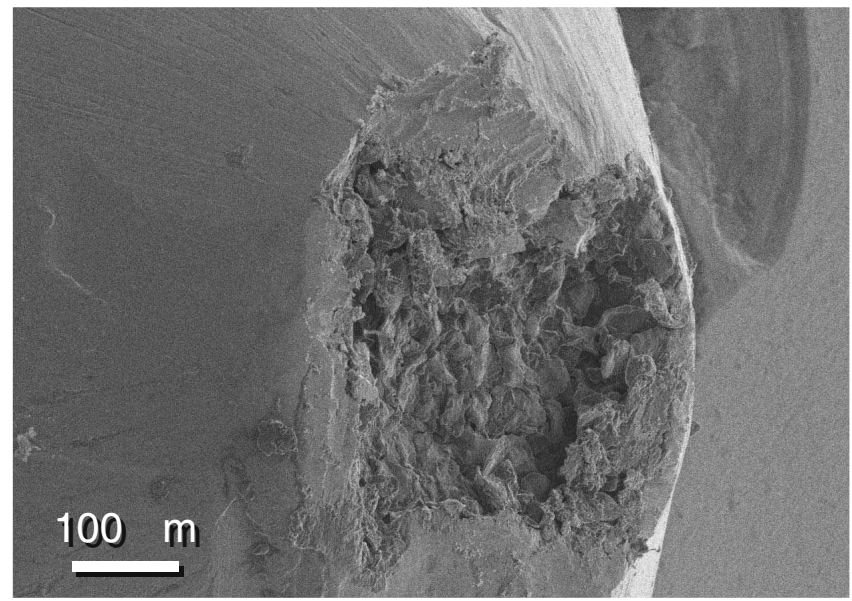

FIG. 10. Secondary electron micrograph of the remnant of a diamond indenter after contact with a steel sample at $500^{\circ} \mathrm{C}$. propriate indenter material for the various classes of sample materials to ensure that the indenter remains chemically inert during indentation.

However, this situation is complicated by the extremely high stresses applied during indentation. An appropriate "rule of thumb" for a maximum temperature for indentation with known reactive indenter/sample combinations, such as staying below the creep regime of the material or below the formation temperature of the carbide, remains elusive, since the tip can be destroyed at temperatures far below either of these criterions - Figure 10. In fact, high precision investigations using sharp diamond indenters on pure tungsten have shown signs of blunting/reactivity even at room temperature, ${ }^{76}$ which further suggests that these reactions occur over a continuum rather than starting at a particular onset temperature.

A systematic empirical study of the influence of stress on these solid state reactions has been avoided thus far due to the prohibitive cost of the number of consumable indenters required to conduct such a study. However, some recent advances have been made for studying the stress-assisted wear of single point diamond tools, ${ }^{63}$ which suggest stress assisted graphitization at high cutting temperatures is the dominant mechanism. In the absence of knowledge of how this extrapolates to the full temperature range and other indenter materials, indenter/sample material combinations where reactions have been observed to occur at any elevated temperature are recommended to be avoided completely.

\section{Reactivity of elemental indenter/sample combinations}

Some limited anecdotal information on safe temperature regimes and indenter/sample material combinations for high temperature indentation exists in the literature on hot hardness from the 1940s to 1960s, but much of this technical expertise seems to have been lost. By combining the limited picture remaining from hot hardness literature with the literature on high temperature wetting and metal-ceramic composite manufacture, a general picture of the reactivities of various classes of indenter/sample material combinations has been constructed - Table IV.

Diamond indenters show excellent resistance to materials which chemically attack indenters: alkali metals, alkaline earth metals, and metalloids. However, diamond is vulnerable to attack by materials which aggressively form carbides or dissolve carbon: the early and late transition metals. Many of the early transition metals have carbides with a high enthalpy of formation, so diamond's reactions with them may not become rapid or apparent until very high temperature. As discussed above, the details of the various reactions' kinetics are not known with stress, so caution is suggested when using a diamond indenter in combination with any of these metals even at relatively low temperatures. Diamond is almost completely inert in combination with the noble and coinage metals, but the literature suggests that the noble metals can also dissolve carbon at high temperatures.

Tungsten carbide appears to be the most chemically stable of all the indenter materials. It only appears to be vulnerable in combination with tungsten, titanium, and iron at 
TABLE IV. Overview of indenter and sample material classes and their reactivities at high temperature. ${ }^{7,11,64-74}$

\begin{tabular}{|c|c|c|c|c|c|c|c|c|}
\hline \multirow[b]{2}{*}{$\begin{array}{l}\text { Indenter } \\
\text { material }\end{array}$} & & \multicolumn{7}{|c|}{ Sample material classes } \\
\hline & & $\begin{array}{l}\text { Alkali metals } \\
\text { Li, Na, K, Rb, } \\
\text { Cs }\end{array}$ & $\begin{array}{l}\text { Alkaline earth } \\
\text { metals } \\
\mathrm{Be}, \mathrm{Mg}, \mathrm{Ca}, \mathrm{Sr}\end{array}$ & $\begin{array}{c}\text { Early transition } \\
\text { metals } \\
\mathrm{Sc}, \mathrm{Ti}, \mathrm{V}, \mathrm{Cr}, \mathrm{Y}, \mathrm{Zr}, \\
\mathrm{Nb}, \mathrm{Mo}, \mathrm{Hf}, \mathrm{Ta}, \mathrm{W}\end{array}$ & Ferrous metals & $\begin{array}{l}\text { Noble metals } \\
\mathrm{Ru}, \mathrm{Rh}, \mathrm{Pd}, \mathrm{Re}, \\
\text { Os, Ir, Pt }\end{array}$ & $\begin{array}{l}\text { Coinage metals } \\
\mathrm{Cu}, \mathrm{Zn}, \mathrm{Ag}, \mathrm{Cd} \text {, } \\
\mathrm{In}, \mathrm{Sn}, \mathrm{Au}, \mathrm{Pb}, \mathrm{Bi}\end{array}$ & $\begin{array}{l}\text { Metalloids } \\
\mathrm{Al}, \mathrm{Si}, \mathrm{Ge}\end{array}$ \\
\hline Diamond & & Inert & Inert & $\begin{array}{l}\text { Dissolves carbon/ } \\
\text { forms carbides }\end{array}$ & $\begin{array}{l}\text { Dissolves carbon, } \\
\text { e.g., } \mathrm{Fe} \sim 400^{\circ} \mathrm{C}\end{array}$ & $\begin{array}{l}\text { Dissolves carbon } \\
>1000^{\circ} \mathrm{C}\end{array}$ & Inert & $\begin{array}{l}\text { Forms } \mathrm{Al}_{4} \mathrm{C}_{3} \\
>700^{\circ} \mathrm{C} \text { with } \\
\mathrm{Al}^{64} \\
\text { Forms } \mathrm{SiC} \\
>1200^{\circ} \mathrm{C}^{65,66} \\
\text { with } \mathrm{Si}\end{array}$ \\
\hline \multirow[t]{3}{*}{ Carbides } & $\mathrm{B}_{4} \mathrm{C}$ & Unknown & Inert & $\begin{array}{l}\mathrm{B}_{4} \mathrm{C} \text { reacts with } \mathrm{Ti} \\
\text { and } \mathrm{Zr}\end{array}$ & $\begin{array}{l}\mathrm{B}_{4} \mathrm{C} \text { forms } \\
\text { borides/carbides }\end{array}$ & Inert & Inert & Forms borides \\
\hline & $\mathrm{SiC}$ & Unknown & Inert & Inert & Dissolves $\mathrm{SiC}^{67}$ & Inert & Inert & $\begin{array}{l}\text { Forms } \mathrm{Al}_{4} \mathrm{C}_{3} \\
\text { with } \mathrm{Al}\end{array}$ \\
\hline & WC & Unknown & Inert & $\begin{array}{l}\text { Mostly inert - may } \\
\text { lose carbon by } \\
\text { diffusion }\end{array}$ & $\begin{array}{l}\text { Mostly inert - } \\
\text { may lose carbon } \\
\text { by diffusion }\end{array}$ & Inert & Inert & Inert \\
\hline Nitrides & $\mathrm{cBN}$ & Unknown & Inert & $\begin{array}{l}\text { Mostly inert } \mathrm{Mo}, \mathrm{Ti} \\
\text { and } \mathrm{Cr} \text { may form } \\
\text { nitrides/borides }\end{array}$ & $\begin{array}{l}\text { Dissolves, e.g., } \\
\mathrm{Ni} \sim 300^{\circ} \mathrm{C}^{7}\end{array}$ & Inert & Inert & $\begin{array}{l}\text { Forms borides } \\
\text { and nitrides }\end{array}$ \\
\hline Oxides & $\mathrm{Al}_{2} \mathrm{O}_{3}$ & Dissolves & $\begin{array}{l}\text { May reduce } \\
\text { oxide }\end{array}$ & $\begin{array}{l}\text { Mostly inert }{ }^{69} \mathrm{Ti} \text { and } \\
\mathrm{Cr} \text { may reduce oxide, } \\
\text { e.g., high Cr steel } \\
\sim 700^{\circ} C^{70}\end{array}$ & $\begin{array}{l}\text { Dissolves, e.g., } \\
\mathrm{Ni} \sim 300^{\circ} \mathrm{C}^{71}\end{array}$ & $\begin{array}{l}\text { Dissolves in } \mathrm{Pd} \\
\text { and } \mathrm{Pt}\end{array}$ & $\begin{array}{l}\text { Dissolves in } \mathrm{Zn} \\
\text { and } \mathrm{Bi}\end{array}$ & $\begin{array}{l}\text { Reduces } \\
\text { oxide, } \text { e.g., } \mathrm{Al} \\
\sim 400^{\circ} \mathrm{C}\end{array}$ \\
\hline
\end{tabular}

very high temperatures where the carbon could diffuse into the sample. This offers an explanation for the widespread usage of WC indenters in the hot hardness literature. Despite its relatively low hardness, WC offers a low cost indenter material which is inert in combination with most materials. For indenting softer metals and alloys, tungsten carbide appears to be the most universal choice.

Both indenter materials which contain boron, $\mathrm{cBN}$ and $\mathrm{B}_{4} \mathrm{C}$, show a similar tendency to react with the more energetic early transition metals, late transition metals, and metalloids as well as with oxygen. The boria, $\mathrm{B}_{2} \mathrm{O}_{3}$, layer which forms during oxidation is suggested to be a passive, protective layer in the literature. However, the thickness of this layer is likely to be on a similar scale to nanoindentation depths, and repetitive removal of the layer by indentation and subsequent regrowth would result in wear of the indenters. Additionally, the layer is irregular and porous, so this will likely cause deviations in diamond area function. This reactivity of boroncontaining materials is expected to be more pronounced in the less strongly covalently bonded borides such as $\mathrm{TiB}_{2}, \mathrm{ZrB}_{2}$, $\mathrm{HfB}_{2}$, and $\mathrm{ReB}_{2}$.

Sapphire, or more accurately corundum, is perhaps the most reactive indenter material. The majority of the transition, noble, and coinage metals are inert in combination with sapphire. However, significant exceptions exist in almost all categories. These are typically alkaline or oxidizing metals such as lithium or aluminium, magnesium and titanium. However, some post transition metals, zinc and bismuth, can also dissolve sapphire. The strongest recommendations for using sapphire are its immunity to oxidation, low cost, and good machinability.

\section{Reactivity of indenters with alloys}

The reactivity of indenter-alloy combinations at elevated temperatures depends on the type of alloying employed: solidsolution, multi-phase, and/or precipitate-strengthened. Solidsolution alloys have decreased reactivity, as compared to the pure metals of the different alloying elements, with the reactivity proportionally decreased by the diffusion mobility and the atomic fraction. However, solid solutions will act to react/blunt an indenter uniformly. Both multi-phase and precipitate-strengthened alloys can react discretely on different regions of the indenter, depending on whether an indentation will transect either an interface between phases or a reactive precipitate. This produces an irregularly shaped indenter which can no longer be analyzed using conventional contact mechanics analyses which assume an axisymmetric indenter (or with a slight correction for polygonal pyramids).

For solid-solution and multi-phase alloys, the elemental reactivities discussed in Sec. V C can serve as a guide for which combinations to avoid. For precipitate strengthened alloys, the reactivity of indenters with ceramics and compounds discussed in Sec. V E should be considered.

\section{E. Reactivity of indenters with ceramics and compounds}

Ceramics and compounds can also react with various indenter materials at very high temperatures. The controlling factor for this is whether the sample compound is more chemically stable than the indenter sample. An example of this would be indenting carbide with another carbide, whichever element has the higher affinity with carbon will 
deplete the other. However, at high temperatures, boron carbide has been successfully used for indenting both borides and carbides. ${ }^{22}$ Diamond, tantalum carbide and tungsten carbide are suggested for indentation of oxides, ${ }^{22}$ nitrides, and semiconductors. ${ }^{75}$

\section{SUMMARY}

The literature properties of various indenter materials have been reviewed with respect to their performance for high temperature nanoindentation. Diamond and boron carbide are the materials of choice for indenting hard materials at elevated temperatures due to their excellent retained hardness at high temperatures. The temperature dependence of the elastic properties of the various indenter materials including formulae for their values has been given along with the possible errors resulting from using incorrect values. The thermal properties of the materials have been briefly described in relation to their impact on high temperature indentation behavior. The influence of thermal expansion on indenter tip geometry was found to be negligible for most indenter materials, and methods for calibrating the thermal gradient between the indenter tip and its temperature sensor were discussed. Lastly, the chemical reactivity of the indenter materials with various elements was reviewed. High to ultra-high vacuum is necessary to prevent oxidation of most indenter materials above $\sim 400{ }^{\circ} \mathrm{C}$ with the exception of sapphire. Tungsten carbide showed the lowest reactivity of the indenter materials surveyed and is likely the most universal solution for indentation of metals and alloys without sample-indenter reactions.

\section{ACKNOWLEDGMENTS}

The authors would like to thank CSM Instruments SA, Pesaux, Switzerland for their support for the initial portion of this review and their continuing efforts to advance high temperature nanoindentation technology. The authors would like to thank the high temperature nanoindentation community for its support for this review and their contributions to Table IV. J.M.W. would like to acknowledge the assistance of R.A. Oliver of the University of Cambridge, UK in acquiring the data for Figures 9(a) and 9(b). J.M.W. would especially like to thank M. Monclus of IMDEA, Madrid, Spain for the contribution of Figure 9(c) and R. Schwaiger of KIT, Karlsruhe, Germany for the inspiration and motivation for this review.

${ }^{1}$ B. D. Beake and J. F. Smith, Philos. Mag. A 82(10), 2179-2186 (2002).

${ }^{2}$ C. A. Schuh, J. K. Mason, and A. C. Lund, Nature Mater. 4(8), 617-621 (2005).

${ }^{3}$ C. A. Schuh, C. E. Packard, and A. C. Lund, J. Mater. Res. 21(3), 725-736 (2006).

${ }^{4}$ J. C. Trenkle, C. E. Packard, and C. A. Schuh, Rev. Sci. Instrum. 81(7), 073901 (2010).

${ }^{5}$ Z. Duan and A. Hodge, JOM 61(12), 32-36 (2009).

${ }^{6}$ J. Milhans, D. S. Li, M. Khaleel, X. Sun, M. S. Al-Haik, A. Harris, and H. Garmestani, J. Power Sources 196(13), 5599-5603 (2011).

${ }^{7}$ N. M. Everitt, M. I. Davies, and J. F. Smith, Philos. Mag. 91(7-9), 12211244 (2011).

${ }^{8}$ S. Korte, R. J. Stearn, J. M. Wheeler, and W. J. Clegg, J. Mater. Res. 27(1), 167-176 (2011).
${ }^{9}$ J. M. Wheeler and J. Michler, Rev. Sci. Instrum. 84(4), 045103 (2013).

${ }^{10}$ B. V. Elsevier, SciVerse $\AA$ Scopus $₫$, September 2013, see http://www. scopus.com/home.url.

${ }^{11}$ J. M. Wheeler, R. A. Oliver, and T. W. Clyne, Diamond Relat. Mater. 19(11), 1348-1353 (2010).

${ }^{12}$ V. Maier, B. Merle, M. Göken, and K. Durst, J. Mater. Res. 28, 1177-1188 (2013).

${ }^{13}$ H. Lee, Y. Chen, A. Claisse, and C. Schuh, Exp. Mech. 53, 1201-1211 (2013).

${ }^{14}$ X. Huang, J. Nohava, B. Zhang, and A. G. Ramirez, Int. J. Smart Nano Mater. 2(1), 39-49 (2011).

${ }^{15}$ F. P. Bowden and D. Tabor, The Friction and Lubrication of Solids (Clarendon, Oxford, 1986).

${ }^{16}$ D. Tabor, Br. J. Appl. Phys. 7, 159-166 (1956).

${ }^{17}$ N. Novikov, Y. V. Sirota, V. Mal'Nev, and I. Petrusha, Diamond Relat. Mater. 2(9), 1253-1256 (1993).

${ }^{18}$ M. Lee, Metall. Trans. A 14(8), 1625-1629 (1983).

${ }^{19}$ A. Atkins, Proc. R. Soc. London, Ser. A 292, 441 (1966).

${ }^{20}$ T. Hirai and K. Niihara, J. Mater. Sci. 14(9), 2253-2255 (1979).

${ }^{21}$ V. Mukhanov, O. Kurakevych, and V. Solozhenko, J. Superhard Mater. 32(3), 167-176 (2010).

${ }^{22}$ R. D. Koester and D. P. Moak, J. Am. Ceram. Soc. 50(6), 290-296 (1967).

${ }^{23}$ S. Otani, M. M. Korsukova, and T. Aizawa, J. Alloys Compd. 477(1-2), L28-L29 (2009).

${ }^{24}$ J. Qian, C. Pantea, J. Huang, T. W. Zerda, and Y. Zhao, Carbon 42(12-13), 2691-2697 (2004).

${ }^{25}$ H.-Y. Chung, M. B. Weinberger, J. B. Levine, A. Kavner, J.-M. Yang, S. H. Tolbert, and R. B. Kaner, Science 316(5823), 436-439 (2007).

${ }^{26}$ V. L. Solozhenko, O. O. Kurakevych, D. Andrault, Y. Le Godec, and M. Mezouar, Phys. Rev. Lett. 102(1), 015506 (2009).

${ }^{27}$ Y. Zhang, H. Sun, and C. Chen, Phys. Rev. Lett. 93(19), 195504 (2004).

${ }^{28}$ V. Solozhenko, O. Kurakevych, and A. Oganov, J. Superhard Mater. 30(6), 428-429 (2008)

${ }^{29}$ N. Dubrovinskaia, L. Dubrovinsky, W. Crichton, F. Langenhorst, and A. Richter, Appl. Phys. Lett. 87(8), 083106 (2005).

${ }^{30}$ D. He, Y. Zhao, L. Daemen, J. Qian, T. Shen, and T. Zerda, Appl. Phys. Lett. 81(4), 643-645 (2002).

${ }^{31}$ W. C. Oliver and G. M. Pharr, J. Mater. Res. 7(6), 1564-1583 (1992).

${ }^{32}$ F. Aguado and V. G. Baonza, Phys. Rev. B 73(2), 024111 (2006).

${ }^{33}$ R. R. Reeber and K. Wang, J. Am. Ceram. Soc. 82(1), 129-135 (1999).

${ }^{34}$ J. B. Wachtman and D. G. Lam, J. Am. Ceram. Soc. 42(5), 254-260 (1959).

${ }^{35}$ J. B. Wachtman, Jr., W. E. Tefft, D. G. Lam, Jr., and C. S. Apstein, Phys. Rev. 122(6), 1754-1759 (1961).

${ }^{36}$ T. Goto, O. L. Anderson, I. Ohno, and S. Yamamoto, J. Geophys. Res. 94(B6), 7588-7602, doi:10.1029/JB094iB06p07588 (1989).

${ }^{37}$ S. R. Murthy, J. Mater. Sci. Lett. 4(5), 603-605 (1985).

${ }^{38}$ W. Köster and W. Rauscher, Z. Metallkd. 39, 111-120 (1948).

${ }^{39} \mathrm{Z}$. Li and R. C. Bradt, Int. J. High Technol. Ceram. 4(1), 1-10 (1988).

${ }^{40}$ H. Doi, Y. Fujiwara, K. Miyake, and Y. Oosawa, Metall. Mater. Trans. 1(5), 1417-1425 (1970).

${ }^{41}$ M. N. Valdez, K. Umemoto, and R. M. Wentzcovitch, Appl. Phys. Lett. 101(17), 171902-171904 (2012).

${ }^{42}$ N. Schwarzer, Philos. Mag. 92(13), 1631-1648 (2012).

${ }^{43}$ J. M. Wheeler, P. Brodard, and J. Michler, Philos. Mag. 92(25-27), 3128$3141(2012)$

${ }^{44}$ A. W. Weimer, Carbide, Nitride and Boride Materials Synthesis and Processing (Springer, 1997).

${ }^{45}$ H. O. Pierson, Handbook of Carbon, Graphite, Diamond and Fullerenes (Noyes publications, 1993).

${ }^{46}$ G. A. Slack, J. Phys. Chem. Solids 34(2), 321-335 (1973).

${ }^{47}$ R. Reeber and K. Wang, J. Electron. Mater. 25(1), 63-67 (1996).

${ }^{48}$ G. A. Slack and S. F. Bartram, J. Appl. Phys. 46(1), 89-98 (1975).

${ }^{49}$ F. Thévenot, J. Eur. Ceram. Soc. 6(4), 205-225 (1990).

${ }^{50}$ J. B. Wachtman, T. G. Scuderi, and G. W. Cleek, J. Am. Ceram. Soc. 45(7), 319-323 (1962).

${ }^{51}$ J. Thurn and R. F. Cook, J. Mater. Res. 17(5), 1143-1146 (2002).

${ }^{52}$ P. Nayar, Proc. Math. Sci. 13(4), 284-290 (1941).

${ }^{53}$ H. Herchen and M. A. Cappelli, Phys. Rev. B 43(14), 11740 (1991).

${ }^{54}$ J. B. Cui, K. Amtmann, J. Ristein, and L. Ley, J. Appl. Phys. 83(12), 7929 7933 (1998)

${ }^{55}$ H. Herchen and M. A. Cappelli, Phys. Rev. B 47(21), 14193 (1993).

${ }^{56}$ T. Kawamoto, K. N. Matsukage, T. Nagai, K. Nishimura, T. Mataki, S. Ochiai, and T. Taniguchi, Rev. Sci. Instrum. 75(7), 2451-2454 (2004). 
${ }^{57}$ M. Ashkin, J. H. Parker, Jr., and D. W. Feldman, Solid State Commun. 6(6), 343-346 (1968).

${ }^{58}$ L. M. Litz and R. Mercuri, J. Electrochem. Soc. 110(8), 921-925 (1963).

${ }^{59}$ J. Quanli, Z. Haijun, L. Suping, and J. Xiaolin, Ceram. Int. 33(2), 309-313 (2007).

${ }^{60}$ A. S. Kurlov and A. I. Gusev, Int. J. Refract. Met. Hard Mater. 41, 300-307 (2013).

${ }^{61}$ S. Lotfian, J. Molina-Aldareguia, K. Yazzie, J. Llorca, and N. Chawla, Philos. Mag. Lett. 92(8), 362-367 (2012).

${ }^{62}$ S. Lotfian, M. Rodríguez, K. Yazzie, N. Chawla, J. Llorca, and J. MolinaAldareguía, Acta Mater. 61(12), 4439-4451 (2013).

${ }^{63}$ Z. Lai, D. Guojun, and Z. Ming, Int. J. Refract. Metals Hard Mater. 41, 174-179 (2013).

${ }^{64}$ S. Kleiner, F. Khalid, P. Ruch, S. Meier, and O. Beffort, Scr. Mater. 55(4), 291-294 (2006).

${ }^{65}$ M. G. S. Naylor and T. F. Page, J. Microsc. 130(JUN), 345-360 (1983).

${ }^{66}$ T. F. Page, personal communication with J. M. Wheeler (20 March 2013).
${ }^{67}$ S. Kalogeropoulou, L. Baud, and N. Eustathopoulos, Acta Metall. Mater. 43(3), 907-912 (1995).

${ }^{68}$ J. A. Arsecularatne, L. C. Zhang, and C. Montross, Int. J. Mach. Tools Manuf. 46(5), 482-491 (2006).

${ }^{69}$ C. H. Philleo and D. H. Sale, U. S. Army Weapons Command, DTIC Report No. SWERR-TR- 72-63, 1972.

${ }^{70}$ S. G. Roberts, personal communication with J. M. Wheeler (6 March 2013).

${ }^{71} \mathrm{P}$. Hosemann, personal communication with J. M. Wheeler (21 March 2013).

${ }^{72}$ N. Eustathopoulos, G. Nicholas and B. Drevet, Wettability at High Temperatures (Elsevier Science, 1999).

${ }^{73}$ G. E. Spriggs, in Powder Metallurgy Data. Refractory, Hard and Intermetallic Materials, edited by P. Beiss, R. Ruthardt, and H. Warlimont (Springer, Berlin Heidelberg, 2012), Vol. 2A2, pp. 118-139.

${ }^{74}$ E. Paul, C. J. Evans, A. Mangamelli, M. L. McGlauflin, and R. S. Polvani, Precis. Eng. 18(1), 4-19 (1996).

${ }^{75}$ I. Yonenaga and T. Suzuki, Philos. Mag. Lett. 82(10), 535-542 (2002).

${ }^{76}$ O. L. Warren, personal communication with J. M. Wheeler (6 March 2013). 